\title{
Impacto da Adoção do SNC na Ótica do Preparador da Informação Financeira
}

\section{Resumo}

Este artigo tem como objetivo estudar o impacto do Sistema de Normalização Contabilística (SNC) - novo normativo contabilístico português - no modelo de informação financeira, na profissão de Técnico Oficial de Contas (TOC) e nas empresas, na perspetiva do preparador da informação financeira. Iniciase com uma revisão da literatura dos estudos mais significativos sobre os impactos e implicações causados pela transição de normativo contabilístico num processo de harmonização e acerca da perceção dos preparadores da informação sobre a mudança de referencial contabilístico. Para o efeito utilizamos uma metodologia qualitativa, assente na análise documental sobre a matéria em estudo e de diplomas contabilísticos. No sentido de desenvolvermos o nosso estudo empírico, submetemos um inquérito por questionário aos preparadores da informação financeira, de modo a obtermos as suas opiniões acerca dos impactos da adoção do novo modelo contabilístico nas vertentes enunciadas. Na ótica do preparador, existe uma grande confiança no novo normativo, dado que este responde às atuais necessidades de relato financeiro, tem em conta as caraterísticas e a realidade das empresas portuguesas, permite a comparabilidade a vários níveis, é mais vantajoso ao nível dos custos de preparação da informação, mais exigente e moderno, melhora a qualidade da divulgação da informação e implica benefícios para a reputação da profissão de TOC. Todavia, existe o risco de dificuldade de compreensibilidade por parte dos utentes da informação, dificuldade dos gestores perceberem as consequências do SNC nas suas demonstrações financeiras (DF) e da evolução no modelo de relato não ser acompanhado por alterações de gestão do negócio.

Palavras-Chave: Harmonização contabilística, POC, SNC, Preparadores da informação, Portugal.

\section{Catarina Filipa Reis Pinheiro Mestre pela Universidade de Aveiro e Técnica de Contabilidade na Acuinova - Grupo Pescanova. Contato: Rua do Aceiro s/n, 3070/732, Coimbra, Portugal, Cep: 86300-000. \\ E-mail: lipa_pinheiro@hotmail.com}

\section{Sérgio Nuno da Silva Ravara Almeida Cruz}

Doutor pela Universidade de Aveiro e Universidade do Minho e Professor da Universidade de Aveiro (ISCA-UA). Contato: Rua Associação Humanitária dos Bombeiros Voluntários de Aveiro, 3810/500, Aveiro, Portugal, Cep: 86300-000.

E-mail: sergio.cruz@ua.pt

Graça Maria do Carmo Azevedo Doutora pelo Instituto Superior de Ciências do Trabalho e da Empresa (ISCTE) e professora da Universidade de Aveiro (ISCAUA). Contato: Rua Associação Humanitária dos Bombeiros Voluntários de Aveiro, 3810/500, Aveiro, Portugal, Cep: 86300-000. E-mail: graca.azevedo@ua.pt 


\section{Introdução}

O desmantelamento das barreiras ao comércio mundial proporcionou o aumento das operações comerciais e financeiras, implicando a sofisticação e complexidade das transações comerciais e, consequentemente, o surgimento de novos desafios à Contabilidade enquanto sistema de informação. Acresce a estratégia da União Europeia assente numa única economia, bolsa de valores e moeda. A sua concretização depende, nomeadamente, da existência do relato financeiro baseado no mesmo modelo contabilístico. Por esse facto, foi desencadeada uma nova estratégia no processo de harmonização contabilística europeia, que culminou no Regulamento 1606/2002, adotando as normas internacionais de contabilidade/normas internacionais de relato financeiro (NIC/NIRF) do International Accounting Standards Board (IASB) adaptadas pela UE - não consta nas referências. Até então a estratégia europeia assentava nas Diretivas Comunitárias, com destaque para as $4 .^{\mathrm{a}}$ e $7 .^{\mathrm{a}}$ Diretivas.

A entrada de Portugal para a Comunidade Económica Europeia obrigou a alterações no modelo contabilístico português de modo a estar coerente com essas Diretivas. Nesse sentido foi aprovado, em 1989, um novo Plano Oficial de Contabilidade (POC), que foi sendo atualizado ao longo dos anos e sido complementado com a emissão de Diretrizes Contabilísticas. A adoção das NIC/NIRF no espaço europeu teve repercussões nos normativos nacionais. Em Portugal, a partir de 2010, foi adotado um novo modelo contabilístico (SNC) assente mais em princípios do que em regras, com o objetivo de harmonização dos modelos contabilísticos nacionais dos Estados Membros com o modelo adotado pela UE.

Quer os impactos decorrentes da aplicação das normas internacionais do IASB quer a harmonização contabilística têm sido alvo de diversos estudos. Todavia, são escassos os estudos que analisam os potenciais impactos da adoção do SNC na perspetiva do preparador da informação financeira. Pelo facto de os existentes serem (quase) na sua totalidade apriorísticos, julgamos pertinente e relevante recolher a opinião desses agentes sobre o SNC após a sua entrada em vigor e de ter sido concluído, pelo menos, um exercício económico. Assim, dada a relevância do tema, para a sociedade em geral, empresas e profissionais de contabilidade, considerámos necessário analisar quais os possíveis impactos da adoção do novo modelo contabilístico em Portugal, na ótica dos preparadores da informação.

Face ao exposto, pretendemos com este trabalho analisar o impacto da adoção do SNC em três pontos de vista distintos: como modelo de informação financeira, ou seja, no âmbito das alterações ao nível de relato financeiro, da internacionalização, harmonização e comparabilidade das entidades, da compreensão, das divulgações e da gestão do negócio; na profissão de TOC, isto é, se existe ou não um maior reconhecimento, uma necessidade de mais e melhores conhecimentos técnicos e novos desafios éticos; e, por fim, nas empresas de forma a concluir qual o nível do impacto nos resultados, na compreensão das DF e na qualidade da informação financeira. Para o efeito, foi elaborado um inquérito por questionário com a finalidade de recolher as opiniões dos preparadores da informação sobre os impactos da adoção do SNC.

O presente trabalho encontra-se organizado em quatro pontos, sendo o primeiro a presente introdução. No ponto 2 apresentamos uma revisão da literatura sobre os impactos e implicações da alteração de modelo contabilístico. O ponto 3 centra-se no nosso estudo empírico e terminamos com a apresentação das principais conclusões do estudo.

\section{Revisão da literatura}

Jermakowicz (2004) previu que a alteração de normativo tivesse impactos relevantes nas DF consolidadas, mais concretamente nos capitais próprios e no resultado líquido. No entanto, Aisbitt (2006) concluiu que, em termos globais, as alterações nos capitais próprios não são relevantes, apesar de em determinadas rubricas as alterações poderem provocar consequências importantes para a análise financeira. Hung e Subramanyam (2007) concluíram que as NIC/NIRF provocam um efeito positivo ao nível do total do ativo e 
dos capitais próprios, sendo que o efeito positivo sobre o resultado líquido é inferior ao dos capitais próprios. No país vizinho, Callao, Jarne e Laínez (2007) obtiveram evidência de que com a transição para as NIC/ NIRF a imagem das empresas cotadas divergia significativamente. Athanasios, Kanellos e Konstanyinos (2007), na Grécia, concluíram que o capital próprio, em confronto com o resultado líquido, cumpre um papel mais importante no novo modelo de relato do que no anterior, e a diferença na quantia do capital próprio é estatisticamente não significativa, contrariamente ao verificado no valor do resultado líquido.

Em Portugal, Guerreiro (2006) concluiu que o grau de preparação das empresas portuguesas para a adoção do novo normativo está diretamente relacionado com a dimensão, internacionalização e tipo de auditor. Cordeiro et al. (2007) concluíram que a adoção das NIC/NIRF condicionou a avaliação financeira das empresas em consequência dos ajustamentos necessários a transição. Nas empresas do PSI 20 não se pode afirmar que as diferenças encontradas entre o POC e as NIC/NIRF sejam estatisticamente significativas, quer ao nível do capital próprio quer do resultado líquido. Esses resultados de Araújo (2010) são consistentes com os apresentados por Cordeiro, Couto e Silva (2007). Costa e Lopes (2010) demonstraram que com a alteração do POC para as normas internacionais as práticas contabilísticas são consideradas menos conservadoras. Noutra vertente, Pinheiro e Lopes (2012) concluíram não ser possível confirmar a hipótese do aumento da relevância da informação contabilística após a adoção das NIC/NIRF.

Na transição para o SNC, apesar de Machado (2012) reconhecer diferenças significativas entre o POC e o SNC, não encontrou impactos significativos de transição ao nível dos rácios e das rubricas das DF, tendo-se verificado um nível de conservadorismo neutro. No mesmo sentido de Cordeiro et al. (2007) e Araújo (2010), não foi possível afirmar que esta alteração provocou diferenças significativas nos capitais próprios e no resultado líquido.

De acordo com o ICAEW (2007), os preparadores da informação consideram que o impacto da adoção das NIC/NIRF no resultado do período foi reduzido ou nulo, que o novo modelo conduz à melhoria da qualidade da informação financeira, facilita a comparabilidade e a sua utilização pelos supervisores e reguladores. Todavia, não houve consenso quanto ao impacto na compreensibilidade pelos investidores e a maioria discorda que as NIC/NIRF provoque alterações ao nível da gestão. Por sua vez, Quagli e Paoloni (2012) concluíram que os preparadores não apoiam favoravelmente a adoção obrigatória das NIRF para as pequenas e médias empresas, porque não melhoraria a comparabilidade.

Aprioristicamente, Santos e Lopes (2010) recolheram evidência de que a maioria dos profissionais da Contabilidade assumia uma posição favorável ao SNC, apesar de existir consenso relativo de que não existiria benefícios para a profissão. Santos e Lopes (2011) concluíram que os preparadores reconhecem vantagens da adoção do SNC, nomeadamente, a comparabilidade internacional, a satisfação da necessidade de um relato financeiro mais exigente e o acompanhamento da modernização contabilística europeia, mas não acreditam que permita uma redução dos custos pela eliminação da dupla contabilidade e consideram que o novo modelo não se adequa à realidade nacional. Porém, reconhecem que a NCRF-PE simplifica a contabilidade para as pequenas entidades, sem colocar em causa a comparabilidade. Não obstante - e contrariamente a Santos e Lopes (2010) -, a profissão será mais valorizada, pois exige melhores competências, vendo-se o TOC obrigado a utilizar com maior frequência o seu julgamento profissional.

Dado que os estudos na ótica do preparador são apriorísticos, decidimos recolher a opinião dos preparadores da informação após a entrada em vigor do SNC. O inquérito que elaborámos teve por base os estudos apresentados do ICAEW (2007) e de Santos e Lopes (2011).

\section{Estudo empírico}

Com o propósito de verificar que tipo de benefícios e riscos resultaram da transição do POC para o SNC, assim como o impacto causado na profissão de TOC, utilizámos o inquérito por questionário como metodologia de recolha de informação. 


\subsection{Método de Recolha de Dados}

O inquérito permite a colocação de questões a um conjunto de indagados, normalmente figurativo de uma população, sobre a situação familiar, profissional e social, de forma a recolher as suas opiniões e os seus comportamentos em relação a opções ou questões humanas e sociais, manifestando as suas expetativas, os seus níveis de conhecimentos ou de consciência de um acontecimento ou problema (Quivy \& Campenhoudt 2008). O nosso estudo tem como objetivo conhecer quais os impactos da adoção do SNC na perspetiva dos preparadores da informação financeira. Desse modo, dado o número elevado de preparadores existentes, o inquérito assegura-nos um melhor processo de obtenção de dados. Saliente-se que o inquérito é uma forma útil e eficiente de recolher informação num curto espaço de tempo. Esta metodologia constitui "uma forma rápida e relativamente barata de recolher um determinado tipo de informação, partindo do princípio de que os inquéritos são suficientemente disciplinados, abandonam as questões supérfluas e avançam para a tarefa principal” (Bell, 1997, p. 100).

O nosso inquérito incidiu sobre todos os preparadores da informação financeira - população-alvo - mais precisamente sobre os TOC e os TC. Todavia, não nos foi possível quantificar a nossa população, pois, apesar de existir informação sobre o número de TOC, é impossível quantificar o número de Técnicos de Contabilidade (TC). De modo a alcançarmos os nossos objetivos, enviámos o nosso inquérito a várias pessoas ligadas profissionalmente à área financeira, através de contactos obtidos pelos autores. Destacamos que, junto desses mesmos indivíduos, solicitámos a divulgação do inquérito com a finalidade de abranger um maior número de sujeitos. Todas as respostas foram obtidas por via eletrónica, durante o segundo trimestre de 2012, sendo que as respostas foram guardadas de forma automática numa base de dados. Por isso, a nossa amostra classifica-se como uma amostragem não probabilística por conveniência, pois foram selecionados membros da população mais acessíveis (Maroco, 2007; e Hill \& Hill, 2008).

Como resultado final, obtivemos 61 respostas de preparadores da informação financeira que constituíram a nossa amostra. Porém a mesma não é representativa da população, pelo que não nos permite generalizar os resultados obtidos. Destacamos que os inquiridos responderam a todas as questões do nosso inquérito, pelo que não existiram respostas em branco.

\subsection{Conteúdo do questionário e tratamento de dados}

A transição para o novo normativo contabilístico (SNC) constitui um marco bastante significante na contabilidade portuguesa, tendo afetado diversas vertentes, não apenas as empresas, mas, também os preparadores da informação financeira. Todo o processo desencadeado por essa nova adoção levou à existência de diversos estudos com as mais distintas finalidades, sendo que eles exerceram influência no desenvolvimento do nosso trabalho, especialmente na elaboração do nosso inquérito.

Três grupos constituem o inquérito por nós apresentado. O primeiro grupo reservou-se a estudar o perfil da nossa amostra: os preparadores da informação financeira, com o desígnio magno de relacionar as caraterísticas do inquirido com as respostas dadas no segundo e terceiro grupos.

O segundo grupo é dividido em três partes. A primeira parte baseada em Santos e Lopes (2011), são abordados diversos aspetos relacionados com a introdução do SNC, como necessidades atuais de relato financeiro (Pinto, 2009; Santos \& Lopes, 2010; Rodrigues, 2010; CNC, 2011), insuficiência do modelo precedente (CNC, 2008; Santos \& Lopes, 2010), prática contabilística portuguesa a par do desenvolvimento europeu (CNC, 2008; Alves \& Antunes, 2010; Rodrigues, 2010), internacionalização das empresas (Callao et al., 2007; CNC, 2008; Grenha, Cravo, Batista e Pontes, 2009), redução de custos pela eliminação da dupla contabilidade (CNC, 2008) e comparabilidade do relato financeiro (Jernakowicz, 2004; ICAEW, 2007; Ferreira \& Ferreira, 2008; Ribeiro, 2010; Quagli \& Paoloni, 2012). Também foi sujeito à opinião dos inquiridos se o novo modelo de relato atende às caraterísticas e à realidade das empresas nacionais (CNC, $2010 \mathrm{e}$ 2011). Na segunda parte do inquérito, assente em ICAEW (2007), pretendeu-se conhecer a opinião dos preparadores sobre algumas possíveis consequências da introdução do novo modelo de relato, nomeadamente 
maior facilidade na comparabilidade entre diversos países europeus (CNC, 2008; Santos \& Lopes, 2011), melhoria da qualidade da divulgação da informação financeira (Jernakowicz, 2004; Guerreiro, 2006; Grenha et al., 2009; Ribeiro, 2010; CNC, 2011; Pinheiro \& Lopes, 2012), maior facilidade na utilização das DF pelos reguladores e supervisores, melhoria da compreensibilidade da informação financeira pelos utentes (Jernakowicz, 2004) e alterações na gestão do negócio. Na última parte deste grupo II, apoiada em Santos e Lopes (2011), tivemos como finalidade abordar as implicações na profissão. Para o efeito, pretendeu-se obter a opinião dos preparadores designadamente sobre algumas das vantagens inerentes à introdução do SNC (Santos \& Lopes, 2010), a aplicação de o justo valor estar muito dependente do juízo profissional (Grenha et al., 2009; Ribeiro, 2010), o aumento do risco da profissão derivado da filosofia que norteia o novo modelo (Correia, 2009; Grenha et al., 2009), o risco de fraude (Pinto, 2009), maior controlo por parte da CNC (Pires, 2009) e o agravamento dos conflitos com "parceiros" como a Autoridade Tributária e os clientes.

O terceiro grupo do inquérito, baseado em ICAEW (2007), está mais direcionado para o efeito nas entidades, uma vez que interroga sobre a perceção dos inquiridos do impacto do SNC nas empresas. A primeira pergunta prende-se com o impacto do SNC no resultado do período em comparação com o antigo modelo (Jernakowicz, 2004; Aisbitt, 2006; Hung \& Subramanyam, 2007; Athanasios et al, 2007; Cordeiro et al., 2007; Araújo, 2010; Machado, 2012). A segunda questão versa sobre o grau de confiança que os preparadores apresentam em relação ao entendimento por parte dos gestores e dos analistas do impacto do SNC nas DF apresentadas. Por fim, a última questão debruça-se o efeito da adoção do SNC na qualidade das DF em comparação com o antigo normativo (especificamente Pinheiro \& Lopes, 2012; mas pode-se ver igualmente a Jernakowicz, 2004; Guerreiro, 2006; Grenha et al., 2009; CNC, 2011).

De acordo com Quivy e Campenhoudt (2008), sempre que estejamos perante a recolha de dados por meio de inquérito a análise estatística dos dados impõe-se. Acresce que os dados recolhidos por questionário não têm significado só por si mesmos, podendo ser úteis somente no âmbito de tratamento estatístico, uma vez que esta análise é mais aprofundada geralmente, sendo os dados mais completos e padronizados à partida. Assim, para esse efeito, utilizámos o programa IBM SPSS (Statistical Package for the Social Sciences) Statistics 20.0 para a análise dos dados.

Para alcançarmos os objetivos a que nos propusemos para os grupos II e III de questões, analisámos os resultados com o apoio de tabelas de distribuição de frequências, uma forma, segundo Pestana e Gageiro (2008), adequada para obter informação relevante das variáveis qualitativas numa análise univariada. $\mathrm{Na}$ análise desses dois grupos, estabelecemos relações entre duas variáveis (análise bivariada), isto é, efetuámos testes estatísticos tendo em conta a profissão desempenhada e o nível do modelo contabilístico aplicado. Para o efeito, recorremos a técnicas não paramétricas, as mais adequadas em conformidade com as escalas utilizadas (Hill \& Hill, 2008). Assim, realizámos o teste do Qui-Quadrado. A aplicação rigorosa do teste do Qui-Quadrado dito "normal" - Qui-Quadrado de Pearson - só é possível quando as seguintes condições se verificam cumulativamente: tamanho da amostra superior a 20, todas as células tenham frequência esperada superior a 1 e quando pelo menos $80 \%$ das células tenham frequências esperadas superiores ou iguais a 5. Contudo, no nosso caso, estes pressupostos não foram cumpridos, o que nos levou a recorrer a outro teste do Qui-Quadrado, concretamente o teste exato de Fisher, como sugerem Maroco (2007), Hill e Hill (2008) e Pestana e Gageiro (2008). Para cada grupo, foi realizado o referido teste, sendo que foram definidas previamente duas hipóteses a testar, para um nível de significância de 0,05.

\subsection{Apresentação e interpretação dos resultados}

Este ponto pretende refletir e analisar os resultados obtidos com o questionário, de forma a concluir quais as opiniões dos preparadores da informação financeira, analisados por nós, acerca da adoção do novo normativo (SNC). Dado que o inquérito ministrado teve por base os estudos do ICAEW (2007) - com a ressalva de que estudo teve como objeto a adoção das NIC/NIRF - e de Santos e Lopes (2011), apresentamos tabelas comparativas dos resultados obtidos. 
O primeiro grupo do questionário reservou-se a estudar o perfil da nossa amostra composta por 61 preparadores da informação financeira, em que cerca de $49 \%$ são TOC, seguindo-se os TC que representam 36\% da amostra e, por fim, 15\% dos indagados enquadram-se numa opção residual. Ressaltamos que, dada a inexpressividade das outras profissões indicadas, algumas não relacionadas com a preparação da informação financeira, decidimos não considerá-las na análise efetuada. Quanto ao normativo contabilístico que estava a ser aplicado pelos inquiridos no momento do preenchimento do inquérito, o SNC modelo PE - foi a opção com o maior número de respostas, o que ilustra o tecido empresarial português, uma vez que o mesmo é constituído na sua maioria por pequenas empresas (Pires, 2010).

\subsubsection{Perceção do impacto no modelo de informação financeira}

Numa primeira parte da análise do impacto do SNC no modelo de informação financeira, podemos afirmar que os inquiridos demonstram uma opinião positiva face às consequências da sua adoção, como se pode verificar pela Tabela 1 .

Tabela 1

Impacto do SNC no modelo de informação financeira - I

\begin{tabular}{|c|c|c|c|c|c|c|}
\hline \multirow[b]{2}{*}{ Afirmação } & \multicolumn{2}{|c|}{ Concordo } & \multicolumn{2}{|c|}{ Sem opinião } & \multicolumn{2}{|c|}{ Discordo } \\
\hline & $\begin{array}{l}\text { Santos } \\
\text { \& Lopes }\end{array}$ & $\begin{array}{l}\text { Nosso } \\
\text { estudo }\end{array}$ & $\begin{array}{l}\text { Santos } \\
\& \text { Lopes }\end{array}$ & $\begin{array}{l}\text { Nosso } \\
\text { estudo }\end{array}$ & $\begin{array}{l}\text { Santos } \\
\& \text { Lopes }\end{array}$ & $\begin{array}{l}\text { Nosso } \\
\text { estudo }\end{array}$ \\
\hline $\begin{array}{l}\text { O SNC responde às necessidades atuais de relato } \\
\text { financeiro }\end{array}$ & $62,06 \%$ & $90,20 \%$ & $19,76 \%$ & $4,90 \%$ & $18,18 \%$ & $4,90 \%$ \\
\hline $\begin{array}{l}\text { O SNC coloca a prática contabilística portuguesa } \\
\text { a par da europeia, sendo um normativo mais } \\
\text { moderno e um impulso para a competitividade }\end{array}$ & $74,83 \%$ & $86,90 \%$ & $11,71 \%$ & $4,90 \%$ & $13,46 \%$ & $8,20 \%$ \\
\hline $\begin{array}{l}\text { O SNC potencia a internacionalização das } \\
\text { empresas }\end{array}$ & $70,28 \%$ & $65,60 \%$ & $15,03 \%$ & $18,00 \%$ & $14,69 \%$ & $16,40 \%$ \\
\hline $\begin{array}{l}\text { O SNC apresenta vantagens ao nível de custos } \\
\text { de preparação da informação contabilística, ao } \\
\text { "eliminar a dupla contabilidade, e racionalizar os } \\
\text { procedimentos de consolidação" }\end{array}$ & $31,47 \%$ & $59,00 \%$ & $21,50 \%$ & $16,40 \%$ & $47,03 \%$ & $24,60 \%$ \\
\hline $\begin{array}{l}\text { O SNC atende às caraterísticas e à realidade das } \\
\text { empresas nacionais }\end{array}$ & $37,24 \%$ & $52,50 \%$ & $17,13 \%$ & $18,00 \%$ & $45,63 \%$ & $29,50 \%$ \\
\hline $\begin{array}{l}\text { A NCRF-PE simplifica o relato financeiro das } \\
\text { pequenas entidades sem prejuízo da sua } \\
\text { comparabilidade com o das restantes empresas }\end{array}$ & $66,26 \%$ & $70,50 \%$ & $13,81 \%$ & $8,20 \%$ & $19,93 \%$ & $21,30 \%$ \\
\hline $\begin{array}{l}\text { O SNC garante a comparabilidade do relato } \\
\text { financeiro entre todas as empresas portuguesas }\end{array}$ & $66,78 \%$ & $63,90 \%$ & $11,01 \%$ & $13,10 \%$ & $22,20 \%$ & $23,00 \%$ \\
\hline $\begin{array}{l}\text { O POC tem vindo a ser insuficiente, carecendo } \\
\text { de revisão técnica em algumas matérias e sendo } \\
\text { omisso na definição de conceitos importantes }\end{array}$ & $61,19 \%$ & $60,7 \%$ & $9,27 \%$ & $14,8 \%$ & $29,55 \%$ & $24,6 \%$ \\
\hline
\end{tabular}

Nota: As escalas utilizadas ao longo do questionário derivam das escaladas usadas em estudos anteriores que serviram de base à nossa investigação.

Fonte: Elaboração própria

A quase totalidade dos profissionais concorda com o facto de o SNC responder às atuais necessidades de relato financeiro, sendo esta a afirmação que apresentou maior subida de percentagem de concordância, cerca de 30 pontos percentuais. Também é de realçar a mudança de posição dos preparadores da informação financeira quanto a dois aspetos. Antes da entrada em vigor do SNC, cerca de $31 \%$ concordavam que o novo modelo proporcionava vantagens ao nível dos custos de preparação da informação 
contabilística contra cerca de $47 \%$ que discordava; após a entrada em vigor, esses agentes passaram a ter uma posição maioritariamente favorável e apenas discordavam cerca de $24 \%$. O estudo de Santos e Lopes (2011) mostra que, no período pré adoção, apenas cerca de 37\% acreditava que o SNC tinha em consideração as características e a realidade das empresas nacionais, enquanto no nosso estudo mais de metade concorda com essa afirmação.

Este cenário leva-nos a deduzir que os profissionais estão confiantes nas implicações do novo normativo no âmbito do relato financeiro, o que poderá ser justificado pela perceção das vantagens do SNC. Tal estado é ilustrado, igualmente, através da elevada percentagem de concordância com o facto de o SNC ser um normativo mais moderno, acompanhando a modernização contabilística europeia de modo a permitir a comparabilidade internacional. Apresentando também uma percentagem de concordância maioritária, os preparadores acreditam que o SNC: visa satisfazer à necessidade de um relato financeiro mais exigente; garante a comparabilidade entre todas as empresas nacionais e na importância da NCRF-PE; e que o POC traduzia um modelo de relato financeiro inadequado para o contexto atual.

Quando comparadas as respostas, tendo em conta a profissão desempenhada e o seu peso no total da amostra, concluímos que as diferenças são quase nulas, isto é, a profissão exercida parece não influenciar a opinião emitida sobre o SNC (Tabela 2).

Pela realização do teste exato de Fisher, fomos testar a afirmação acima descrita com as seguintes hipóteses: HO - As opiniões (I) sobre as implicaçães do SNC como modelo de informação financeira são independentes da função desempenhada; Ha - As opiniões (I) sobre as implicações do SNC como modelo de informação financeira não são independentes da função desempenhada.

Tabela 2

Impacto do SNC no modelo de informação financeira (I) vs. Função desempenhada

\begin{tabular}{|c|c|c|c|c|c|c|}
\hline \multirow[b]{2}{*}{ Afirmação } & \multirow{2}{*}{$\begin{array}{l}\text { Profissão } \\
\text { Exercida }\end{array}$} & \multirow[b]{2}{*}{ Concordo } & \multirow{2}{*}{$\begin{array}{l}\text { Sem } \\
\text { Opinião }\end{array}$} & \multirow[b]{2}{*}{ Discordo } & \multicolumn{2}{|c|}{ Teste exato de Fisher } \\
\hline & & & & & Valor & $\begin{array}{l}\text { Sig. Exata } \\
\text { (2-abas) }\end{array}$ \\
\hline \multirow{2}{*}{$\begin{array}{l}\text { O SNC responde às necessidades atuais de } \\
\text { relato financeiro }\end{array}$} & TOC & 25 & 2 & 3 & \multirow{2}{*}{,882 } & \multirow{2}{*}{, 581} \\
\hline & TC & 21 & 1 & 0 & & \\
\hline \multirow{2}{*}{$\begin{array}{l}\text { O SNC coloca a prática contabilística } \\
\text { portuguesa a par da europeia, sendo um } \\
\text { normativo mais moderno e um impulso para } \\
\text { a competitividade }\end{array}$} & TOC & 27 & 1 & 2 & \multirow{2}{*}{1,869} & \multirow{2}{*}{883} \\
\hline & TC & 18 & 2 & 2 & & \\
\hline \multirow{2}{*}{$\begin{array}{l}\text { O SNC potencia a internacionalização das } \\
\text { empresas }\end{array}$} & TOC & 18 & 7 & 5 & \multirow{2}{*}{1,610} & \multirow{2}{*}{, 826} \\
\hline & $\mathrm{TC}$ & 16 & 3 & 3 & & \\
\hline \multirow{2}{*}{$\begin{array}{l}\text { O SNC apresenta vantagens ao nível de custos } \\
\text { de preparação da informação contabilística, ao } \\
\text { "eliminar a dupla contabilidade, e racionalizar } \\
\text { os procedimentos de consolidação" }\end{array}$} & TOC & 17 & 4 & 9 & \multirow{2}{*}{5,054} & \multirow{2}{*}{274} \\
\hline & TC & 11 & 5 & 6 & & \\
\hline \multirow{2}{*}{$\begin{array}{l}\text { O SNC atende às caraterísticas e à realidade } \\
\text { das empresas nacionais }\end{array}$} & TOC & 14 & 4 & 12 & \multirow{2}{*}{4,486} & \multirow{2}{*}{, 345} \\
\hline & TC & 14 & 4 & 4 & & \\
\hline \multirow{2}{*}{$\begin{array}{l}\text { A NCRF-PE simplifica o relato financeiro das } \\
\text { pequenas entidades sem prejuízo da sua } \\
\text { comparabilidade com o resto das empresas }\end{array}$} & TOC & 19 & 2 & 9 & \multirow{2}{*}{5,628} & \multirow{2}{*}{, 190 } \\
\hline & TC & 17 & 1 & 4 & & \\
\hline \multirow{2}{*}{$\begin{array}{l}\text { O SNC garante a comparabilidade do } \\
\text { relato financeiro entre todas as empresas } \\
\text { portuguesas }\end{array}$} & TOC & 18 & 5 & 7 & \multirow{2}{*}{0,874} & \multirow{2}{*}{,970 } \\
\hline & TC & 15 & 2 & 5 & & \\
\hline \multirow{2}{*}{$\begin{array}{l}\text { O POC foi insuficiente, carecendo de revisão } \\
\text { técnica em algumas matérias e sendo omisso } \\
\text { na definição de conceitos importantes }\end{array}$} & TOC & 17 & 4 & 9 & \multirow{2}{*}{1,732} & \multirow{2}{*}{842} \\
\hline & TC & 15 & 3 & 4 & & \\
\hline
\end{tabular}

Fonte: Elaboração própria 
De acordo com os resultados apresentados na Tabela 2, não rejeitamos a hipótese nula, uma vez que o valor de $p$-value é superior a 0,05 em todas as informações, o que nos permite concluir que a opinião emitida pelo inquirido é independente da sua função profissional.

A mesma análise foi efetuada quanto ao normativo contabilístico aplicado pelos preparadores da informação financeira no momento do preenchimento do inquérito. Por meio da Tabela 4, constatamos que os nossos inquiridos têm, geralmente, uma opinião favorável do modelo, independentemente de utilizarem no desempenho da sua atividade profissional o modelo geral do SNC ou modelo para as pequenas entidades.

Realce, no entanto, para o facto de apenas a maioria dos preparadores em NCRF-PE concordarem que o $\mathrm{SNC}$ atende às caraterísticas da realidade das empresas nacionais, com os reflexos correspondentes sobre a insuficiência do POC. De notar que a esta última constatação é reconhecida pela maioria dos inquiridos, mas sobretudo pela maioria dos preparadores que utilizaram o POC na sua atividade profissional, conforme mostramos na Tabela 3 - 28 dos inquiridos que aplicaram o POC foram os mais concordantes com a insuficiência do normativo em causa.

Tabela 3

Aplicação do POC vs. Opinião sobre a insuficiência do mesmo

\begin{tabular}{cccc}
\cline { 2 - 4 } & \multicolumn{4}{c}{ Afirmação } \\
\cline { 2 - 4 } & \multicolumn{3}{c}{$\begin{array}{c}\text { Durante o exercício da sua atividade } \\
\text { profissional aplicou o POC? }\end{array}$} \\
\hline Resposta & Sim & Não & Total \\
\hline Concordo & 28 & 9 & 37 \\
\hline Sem Opinião & 5 & 4 & 9 \\
\hline Discordo & 13 & $\mathbf{2}$ & 15 \\
\hline Total & $\mathbf{4 6}$ & $\mathbf{1 5}$ & $\mathbf{6 1}$ \\
\hline
\end{tabular}

O POC foi insuficiente, carecendo de revisão técnica em algumas matérias e sendo omisso na definição de conceitos importantes

Fonte: Elaboração própria

Para verificar se de facto a opinião emitida é ou não afetada pelo normativo contabilístico utilizado, testámos as seguintes hipóteses: HO - As opiniões sobre as implicações do SNC como modelo de informação financeira são independentes do referencial normativo; $\mathrm{Ha}$ - As opiniões sobre as implicações do SNC como modelo de informação financeira não são independentes do referencial normativo. 
Tabela 4

Impacto do SNC no modelo de informação financeira (I) vs. Normativo aplicado

\begin{tabular}{|c|c|c|c|c|c|c|}
\hline \multirow[b]{2}{*}{ Afirmação } & \multirow{2}{*}{$\begin{array}{l}\text { Modelo } \\
\text { aplicado }\end{array}$} & \multirow[b]{2}{*}{ Concordo } & \multirow{2}{*}{$\begin{array}{c}\text { Sem } \\
\text { Opinião }\end{array}$} & \multirow[b]{2}{*}{ Discordo } & \multicolumn{2}{|c|}{ Teste exato de Fisher } \\
\hline & & & & & Valor & $\begin{array}{l}\text { Sig. Exata } \\
\text { (2-abas) }\end{array}$ \\
\hline \multirow{2}{*}{$\begin{array}{l}\text { O SNC responde às necessidades atuais de } \\
\text { relato financeiro }\end{array}$} & SNC - geral & 22 & 2 & 0 & \multirow{2}{*}{,132 } & \multirow{2}{*}{, 379} \\
\hline & SNC - PE & 28 & 1 & 2 & & \\
\hline \multirow{2}{*}{$\begin{array}{l}\text { O SNC coloca a prática contabilística } \\
\text { portuguesa a par da europeia, sendo um } \\
\text { normativo mais moderno e um impulso para } \\
\text { a competitividade }\end{array}$} & SNC - geral & 19 & 2 & 3 & \multirow{2}{*}{,090 } & \multirow{2}{*}{, 761} \\
\hline & SNC - PE & 28 & 1 & 2 & & \\
\hline \multirow{2}{*}{$\begin{array}{l}\text { O SNC potencia a internacionalização das } \\
\text { empresas }\end{array}$} & SNC - geral & 15 & 4 & 5 & \multirow{2}{*}{, 526} & \multirow{2}{*}{,465 } \\
\hline & SNC - PE & 21 & 7 & 3 & & \\
\hline \multirow{2}{*}{$\begin{array}{l}\text { O SNC apresenta vantagens ao } \\
\text { nível de custos de preparação da } \\
\text { informação contabilística, ao "eliminar } \\
\text { a dupla contabilidade, e racionalizar os } \\
\text { procedimentos de consolidação" }\end{array}$} & SNC - geral & 14 & 2 & 8 & \multirow{2}{*}{,992 } & \multirow{2}{*}{, 571} \\
\hline & SNC - PE & 18 & 7 & 6 & & \\
\hline \multirow{2}{*}{$\begin{array}{l}\text { O SNC atende às caraterísticas e à realidade } \\
\text { das empresas nacionais }\end{array}$} & SNC - geral & 11 & 4 & 9 & \multirow{2}{*}{,692 } & \multirow{2}{*}{,633 } \\
\hline & SNC - PE & 17 & 7 & 7 & & \\
\hline \multirow{2}{*}{$\begin{array}{l}\text { A NCRF-PE simplifica o relato financeiro das } \\
\text { pequenas entidades sem prejuízo da sua } \\
\text { comparabilidade com o resto das empresas }\end{array}$} & SNC - geral & 17 & 3 & 4 & \multirow{2}{*}{, 557} & \multirow{2}{*}{872} \\
\hline & SNC - PE & 21 & 2 & 8 & & \\
\hline \multirow{2}{*}{$\begin{array}{l}\text { O SNC garante a comparabilidade do } \\
\text { relato financeiro entre todas as empresas } \\
\text { portuguesas }\end{array}$} & SNC - geral & 14 & 4 & 6 & \multirow{2}{*}{, 589} & \multirow{2}{*}{, 842} \\
\hline & SNC - PE & 21 & 4 & 6 & & \\
\hline \multirow{2}{*}{$\begin{array}{l}\text { O POC foi insuficiente, carecendo de } \\
\text { revisão técnica em algumas matérias e } \\
\text { sendo omisso na definição de conceitos } \\
\text { importantes }\end{array}$} & SNC - geral & 12 & 3 & 9 & \multirow{2}{*}{,626 } & \multirow{2}{*}{,452 } \\
\hline & SNC - PE & 21 & 5 & 5 & & \\
\hline
\end{tabular}

Fonte: Elaboração própria

Atendendo aos resultados obtidos (Tabela 4), não rejeitamos a hipótese nula, pois o valor do $p$-value é sempre superior a 0,05 . Neste grupo podemos afirmar que as respostas dadas não foram influenciadas pelo normativo aplicado pelo indagado.

Ainda na mesma área de análise, atendendo aos resultados expressos na Tabela 5, destacamos que a maioria considerou que a aplicação do novo normativo facilita a comparação da informação financeira entre empresas de diferentes países europeus e entre empresas do mesmo setor. De notar ainda que mais de metade dos inquiridos concordou que o novo modelo contabilístico melhorou a qualidade da divulgação nas DF e que permite uma mais fácil utilização dessas pelos supervisores e reguladores. Todavia, os preparadores têm respostas diversas sobre o impacto na compreensibilidade da informação financeira pelos utentes. De realçar que, em termos gerais, estas opiniões vão de encontro às conclusões do ICAEW (2007) sobre a transição, num patamar superior, das normas nacionais para as NIC/NIRF da UE no foro das contas consolidadas. 
Tabela 5

Impacto do SNC como modelo de informação financeira (II)

\begin{tabular}{|c|c|c|c|c|c|c|c|c|c|c|}
\hline \multirow{2}{*}{ Afirmação } & \multicolumn{2}{|c|}{$\begin{array}{l}\text { Concordo } \\
\text { muito }\end{array}$} & \multicolumn{2}{|c|}{ Concordo } & \multicolumn{2}{|c|}{$\begin{array}{l}\text { Não discordo } \\
\text { nem concordo }\end{array}$} & \multicolumn{2}{|c|}{ Discordo } & \multicolumn{2}{|c|}{$\begin{array}{l}\text { Discordo } \\
\text { muito }\end{array}$} \\
\hline & Icaew & $\begin{array}{l}\text { Nosso } \\
\text { estudo }\end{array}$ & Icaew & $\begin{array}{l}\text { Nosso } \\
\text { estudo }\end{array}$ & Icaew & $\begin{array}{l}\text { Nosso } \\
\text { estudo }\end{array}$ & Icaew & $\begin{array}{l}\text { Nosso } \\
\text { estudo }\end{array}$ & Icaew & $\begin{array}{l}\text { Nosso } \\
\text { estudo }\end{array}$ \\
\hline $\begin{array}{l}\text { O SNC tornou a informação } \\
\text { financeira mais fácil de } \\
\text { comparar entre os diversos } \\
\text { países europeus }\end{array}$ & $36 \%$ & $14,80 \%$ & $36 \%$ & $62,30 \%$ & $9 \%$ & $11,50 \%$ & $8 \%$ & $9,80 \%$ & $7 \%$ & $1,60 \%$ \\
\hline $\begin{array}{l}\text { O SNC tornou a } \\
\text { comparação da informação } \\
\text { financeira entre empresas } \\
\text { do mesmo setor mais fácil }\end{array}$ & $32 \%$ & $14,80 \%$ & $36 \%$ & $62,30 \%$ & $15 \%$ & $14,80 \%$ & $9 \%$ & $6,60 \%$ & $7 \%$ & $1,60 \%$ \\
\hline $\begin{array}{l}\text { O SNC melhorou a } \\
\text { qualidade de divulgação } \\
\text { nas demonstrações } \\
\text { financeiras }\end{array}$ & $28 \%$ & $16,40 \%$ & $38 \%$ & $54,10 \%$ & $12 \%$ & $18,00 \%$ & $11 \%$ & $11,50 \%$ & $9 \%$ & $0,00 \%$ \\
\hline $\begin{array}{l}\text { O SNC tornou mais } \\
\text { fácil a utilização das } \\
\text { demonstrações financeiras } \\
\text { pelos reguladores e } \\
\text { supervisores }\end{array}$ & $18 \%$ & $11,50 \%$ & $37 \%$ & $52,50 \%$ & $17 \%$ & $27,90 \%$ & $12 \%$ & $8,20 \%$ & $8 \%$ & $0,00 \%$ \\
\hline $\begin{array}{l}\text { O SNC tornou a informação } \\
\text { financeira de mais fácil } \\
\text { compreensão para os } \\
\text { utentes }\end{array}$ & $12 \%$ & $11,50 \%$ & $30 \%$ & $34,40 \%$ & $14 \%$ & $23,00 \%$ & $23 \%$ & $27,90 \%$ & $17 \%$ & $3,30 \%$ \\
\hline $\begin{array}{l}\text { O SNC provocou alterações } \\
\text { na gestão do negócio }\end{array}$ & $7 \%$ & $3,30 \%$ & $18 \%$ & $29,50 \%$ & $22 \%$ & $31,10 \%$ & $17 \%$ & $27,90 \%$ & $35 \%$ & $8,20 \%$ \\
\hline
\end{tabular}

Fonte: Elaboração própria

Conforme a Tabela 6, apenas quanto à melhoria da compreensão da informação financeira pelos utentes e à alteração na gestão dos negócios se verificam opiniões dispersas em ambas as funções. No seguimento testámos se as respostas recolhidas foram ou não influenciadas pela profissão exercida pelo inquirido. Assim, as hipóteses foram: HO - As opiniões (II) sobre as implicações do SNC como modelo de informação financeira são independentes da função desempenhada; Ha: As opiniões (II) sobre as implicaçães do SNC como modelo de informação financeira não são independentes da função desempenhada. 
Tabela 6

Impacto do SNC como modelo de informação financeira (II) vs. Função desempenhada

\begin{tabular}{|c|c|c|c|c|c|c|c|c|}
\hline \multirow[b]{2}{*}{ Afirmação } & \multirow[b]{2}{*}{$\begin{array}{l}\text { Profissão } \\
\text { Exercida }\end{array}$} & \multirow[b]{2}{*}{$\begin{array}{l}\text { Concordo } \\
\text { Muito }\end{array}$} & \multirow[b]{2}{*}{ Concordo } & \multirow{2}{*}{$\begin{array}{l}\text { Não } \\
\text { discordo } \\
\text { nem } \\
\text { concordo }\end{array}$} & \multirow[b]{2}{*}{ Discordo } & \multirow[b]{2}{*}{$\begin{array}{l}\text { Discordo } \\
\text { Muito }\end{array}$} & \multicolumn{2}{|c|}{ Teste exato de Fisher } \\
\hline & & & & & & & Valor & $\begin{array}{l}\text { Sig. Exata } \\
\text { (2-abas) }\end{array}$ \\
\hline \multirow{2}{*}{$\begin{array}{l}\text { O SNC tornou a informação } \\
\text { financeira mais fácil de } \\
\text { comparar entre os diversos } \\
\text { países europeus }\end{array}$} & TOC & 3 & 20 & 4 & 2 & 1 & \multirow{2}{*}{874} & \multirow{2}{*}{ 704 } \\
\hline & TC & 5 & 12 & 3 & 2 & 0 & & \\
\hline \multirow{2}{*}{$\begin{array}{l}\text { O SNC tornou a } \\
\text { comparação da informação } \\
\text { financeira entre empresas } \\
\text { do mesmo setor mais fácil }\end{array}$} & TOC & 2 & 20 & 5 & 2 & 1 & \multirow{2}{*}{,364 } & \multirow{2}{*}{,480 } \\
\hline & TC & 4 & 13 & 4 & 1 & 0 & & \\
\hline \multirow{2}{*}{$\begin{array}{l}\text { O SNC melhorou a } \\
\text { qualidade de divulgação } \\
\text { nas demonstrações } \\
\text { financeiras }\end{array}$} & TOC & 6 & 13 & 5 & 6 & 0 & \multirow{2}{*}{,944 } & \multirow{2}{*}{, 555} \\
\hline & TC & 3 & 14 & 4 & 1 & 0 & & \\
\hline \multirow{2}{*}{$\begin{array}{l}\text { O SNC tornou mais } \\
\text { fácil a utilização das } \\
\text { demonstrações financeiras } \\
\text { pelos reguladores e } \\
\text { supervisores }\end{array}$} & TOC & 5 & 11 & 11 & 3 & 0 & \multirow{2}{*}{,344 } & \multirow{2}{*}{,248 } \\
\hline & TC & 2 & 15 & 3 & 2 & 0 & & \\
\hline \multirow{2}{*}{$\begin{array}{l}\text { O SNC tornou a informação } \\
\text { financeira de mais fácil } \\
\text { compreensão para os } \\
\text { utentes }\end{array}$} & TOC & 3 & 8 & 8 & 10 & 1 & \multirow{2}{*}{ 263 } & \multirow{2}{*}{,960 } \\
\hline & TC & 3 & 9 & 4 & 5 & 1 & & \\
\hline \multirow{2}{*}{$\begin{array}{l}\text { O SNC provocou alterações } \\
\text { na gestão do negócio }\end{array}$} & TOC & 2 & 5 & 10 & 10 & 3 & \multirow{2}{*}{ 146 } & \multirow{2}{*}{,496 } \\
\hline & TC & 0 & 10 & 6 & 4 & 2 & & \\
\hline
\end{tabular}

Fonte: Elaboração própria

Analisando a Tabela 6, concluímos que as variáveis são independentes entre si em todas as afirmações, dado que o valor do p-value é sempre superior ao nível de significância 0,05.

Refira-se que através da Tabela 7 é visível que apenas quanto à melhoria da compreensão da informação financeira pelos utentes e à alteração na gestão dos negócios se verificam opiniões dispersas nos dois normativos utilizados. Testámos se estas mesmas opiniões se diferenciam significativamente consoante o normativo aplicado. Assim, as hipóteses foram: HO - As opiniões (II) sobre as implicações do SNC como modelo de informação financeira são independentes do referencial normativo; Ha - As opiniões (II) sobre as implicações do SNC como modelo de informação financeira não são independentes do referencial normativo. 
Tabela 7

Impacto do SNC como modelo de informação financeira (II) vs. Normativo aplicado

\begin{tabular}{|c|c|c|c|c|c|c|c|c|}
\hline \multirow[b]{2}{*}{ Afirmação } & \multirow[b]{2}{*}{$\begin{array}{l}\text { Modelo } \\
\text { aplicado }\end{array}$} & \multirow[b]{2}{*}{$\begin{array}{l}\text { Concordo } \\
\text { muito }\end{array}$} & \multirow[b]{2}{*}{ Concordo } & \multirow{2}{*}{$\begin{array}{l}\text { Não } \\
\text { discordo } \\
\text { nem } \\
\text { concordo }\end{array}$} & \multirow[b]{2}{*}{ Discordo } & \multirow[b]{2}{*}{$\begin{array}{l}\text { Discordo } \\
\text { muito }\end{array}$} & \multicolumn{2}{|c|}{ Teste exato de Fisher } \\
\hline & & & & & & & Valor & $\begin{array}{c}\text { Sig. Exata } \\
\text { (2-abas) }\end{array}$ \\
\hline \multirow{2}{*}{$\begin{array}{l}\text { O SNC tornou a } \\
\text { informação financeira } \\
\text { mais fácil de comparar } \\
\text { entre os diversos países } \\
\text { europeus }\end{array}$} & SNC - geral & 4 & 12 & 2 & 5 & 1 & \multirow{2}{*}{,464 } & \multirow{2}{*}{,335 } \\
\hline & SNC - PE & 5 & 21 & 4 & 1 & & & \\
\hline \multirow{2}{*}{$\begin{array}{l}\text { O SNC tornou a } \\
\text { comparação da } \\
\text { informação financeira } \\
\text { entre empresas do } \\
\text { mesmo setor mais fácil }\end{array}$} & SNC - geral & 4 & 12 & 5 & 2 & 1 & \multirow[b]{2}{*}{,379 } & \multirow[b]{2}{*}{,784 } \\
\hline & SNC - PE & 4 & 22 & 3 & 2 & 0 & & \\
\hline \multirow{2}{*}{$\begin{array}{l}\text { O SNC melhorou a } \\
\text { qualidade de divulgação } \\
\text { nas demonstrações } \\
\text { financeiras }\end{array}$} & SNC - geral & 2 & 14 & 6 & 2 & 0 & \multirow{2}{*}{,855 } & \multirow{2}{*}{, 542} \\
\hline & SNC - PE & 6 & 17 & 4 & 4 & 0 & & \\
\hline \multirow{2}{*}{$\begin{array}{l}\text { O SNC tornou mais } \\
\text { fácil a utilização das } \\
\text { demonstrações } \\
\text { financeiras pelos } \\
\text { reguladores e } \\
\text { supervisores }\end{array}$} & SNC - geral & 2 & 15 & 3 & 4 & 0 & \multirow{2}{*}{,132 } & \multirow{2}{*}{,116 } \\
\hline & SNC - PE & 4 & 13 & 13 & 1 & 0 & & \\
\hline \multirow{2}{*}{$\begin{array}{l}\text { O SNC tornou a } \\
\text { informação financeira de } \\
\text { mais fácil compreensão } \\
\text { para os utentes }\end{array}$} & SNC - geral & 2 & 9 & 4 & 7 & 2 & \multirow{2}{*}{,432 } & \multirow{2}{*}{,745 } \\
\hline & SNC - PE & 4 & 9 & 9 & 9 & 0 & & \\
\hline \multirow{2}{*}{$\begin{array}{l}\text { O SNC provocou } \\
\text { alterações na gestão do } \\
\text { negócio }\end{array}$} & SNC - geral & 0 & 6 & 9 & 7 & 2 & \multirow{2}{*}{,593 } & \multirow{2}{*}{, 720} \\
\hline & SNC - PE & 1 & 9 & 9 & 9 & 3 & & \\
\hline
\end{tabular}

Fonte: Elaboração própria

Os resultados expressos na Tabela 7 permitem-nos concluir que as opiniões obtidas sobre o impacto do SNC no modelo de informação financeira não foram influenciadas pelo normativo aplicado pelo indagado.

\subsubsection{Perceção do impacto na profissão}

As respostas obtidas dos preparadores (Tabela 8) sobre o impacto do SNC na profissão de TOC demonstram que os inquiridos concordam que o SNC é um veículo de valorização da profissão, que as caraterísticas do SNC tornam o exercício da profissão mais arriscado e que será necessário mais colaboração por parte dos clientes na prestação da informação. A concordância mantém-se relativamente ao aumento dos conflitos entre os técnicos de contabilidade e a Administração Fiscal (designada atualmente de Autoridade Tributária) e ao maior controlo da profissão por parte da Comissão de Normalização Contabilísti$\mathrm{ca}(\mathrm{CNC})$. Todavia, o aumento dos conflitos entre técnicos e clientes e o facto de o SNC potenciar o risco de fraude são aspetos que os nossos inquiridos discordam. 
Tabela 8

Impacto do SNC na profissão

\begin{tabular}{|c|c|c|c|c|c|c|}
\hline \multirow[b]{2}{*}{ Afirmação } & \multicolumn{2}{|c|}{ Concordo } & \multicolumn{2}{|c|}{ Sem opinião } & \multicolumn{2}{|c|}{ Discordo } \\
\hline & $\begin{array}{l}\text { Santos } \\
\text { \& Lopes }\end{array}$ & $\begin{array}{l}\text { Nosso } \\
\text { estudo }\end{array}$ & $\begin{array}{l}\text { Santos } \\
\text { \& Lopes }\end{array}$ & $\begin{array}{l}\text { Nosso } \\
\text { estudo }\end{array}$ & $\begin{array}{l}\text { Santos } \\
\text { \& Lopes }\end{array}$ & $\begin{array}{l}\text { Nosso } \\
\text { estudo }\end{array}$ \\
\hline $\begin{array}{l}\text { O SNC é um "fator de promoção, coesão e } \\
\text { internacionalização da profissão" }\end{array}$ & $60,31 \%$ & $67,20 \%$ & $16,78 \%$ & $19,00 \%$ & $22,90 \%$ & $13,10 \%$ \\
\hline $\begin{array}{l}\text { O justo valor quando é aplicável, está muito } \\
\text { dependente do juízo profissional e, como tal, está } \\
\text { associado a um risco elevado }\end{array}$ & $78,50 \%$ & $70,50 \%$ & $11,54 \%$ & $16,40 \%$ & $9,97 \%$ & $13,20 \%$ \\
\hline $\begin{array}{l}\text { O SNC torna a profissão de técnico de } \\
\text { contabilidade mais arriscada, uma vez que tem por } \\
\text { base princípios e não regras }\end{array}$ & $83,74 \%$ & $63,90 \%$ & $6,47 \%$ & $4,90 \%$ & $9,79 \%$ & $31,10 \%$ \\
\hline O SNC potencia o risco de fraude & $40,73 \%$ & $21,30 \%$ & $29,90 \%$ & $29,50 \%$ & $29,37 \%$ & $49,20 \%$ \\
\hline $\begin{array}{l}\text { Os conflitos entre os técnicos de contabilidade e a } \\
\text { Administração Fiscal tendem a agravar-se }\end{array}$ & $62,59 \%$ & $50,80 \%$ & $18,01 \%$ & $13,10 \%$ & $19,41 \%$ & $36,10 \%$ \\
\hline $\begin{array}{l}\text { Com o SNC, a profissão de técnico de contabilidade } \\
\text { vai ser mais controlada pela CNC e é expectável } \\
\text { que sejam aplicadas coimas a quem não cumprir }\end{array}$ & $63,46 \%$ & $49,20 \%$ & $19,06 \%$ & $31,10 \%$ & $17,48 \%$ & $19,70 \%$ \\
\hline $\begin{array}{l}\text { Os conflitos entre os técnicos de contabilidade e os } \\
\text { clientes tendem a agravar-se }\end{array}$ & $68,01 \%$ & $34,40 \%$ & $9,97 \%$ & $21,30 \%$ & $22,03 \%$ & $44,30 \%$ \\
\hline $\begin{array}{l}\text { Os técnicos de contabilidade necessitam de mais } \\
\text { das informações fornecidas pelos clientes }\end{array}$ & $87,06 \%$ & $72,1 \%$ & $4,90 \%$ & $13,2 \%$ & $8,04 \%$ & $14,8 \%$ \\
\hline
\end{tabular}

Fonte: Elaboração própria

Da comparação com o estudo de Santos e Lopes (2011) verifica-se que os preparadores acreditam cada vez mais na valorização da profissão, provavelmente em parte justificada pela maior exigência da utilização do seu julgamento profissional. Por outro lado, o nosso estudo mostra que, possivelmente, a experiência dos primeiros anos de SNC provocou uma redução substancial de preparadores que consideram que os conflitos com a Autoridade Tributária e com os clientes podem aumentar. Também fica patente que existe uma redução dos preparadores que concordam que o novo modelo pode ser causa de fraudes e de existir um controlo mais apertado da CNC no que respeita ao exercício da profissão.

Na Tabela 9, filtrámos as respostas segundo a profissão desempenhada. Por um lado, em termos de maioria, quer os TOC quer os TC, ostentam as mesmas opiniões. Por outro lado, a maioria dos TC considera que o SNC não é, por si próprio, um risco de fraude, que os conflitos com a Autoridade Tributária podem agravar-se - ao contrário de com os clientes - e que haverá um controlo mais apertado por parte da CNC ao exercício da profissão, mas sobre estes temas não existe consenso por parte dos TOC.

Para podermos verificar se estas diferenças são estatisticamente significativas testámos as seguintes hipóteses: HO - As opiniões sobre as implicações do SNC na profissão de TOC são independentes da função desempenhada; Ha - As opiniões sobre as implicações do SNC na profissão de TOC não são independentes da função desempenhada. 
Tabela 9

Perceção sobre o impacto do SNC na profissão vs. Função desempenhada

\begin{tabular}{|c|c|c|c|c|c|c|}
\hline \multirow[b]{2}{*}{ Afirmação } & \multirow[b]{2}{*}{$\begin{array}{l}\text { Profissão } \\
\text { Exercida }\end{array}$} & \multirow[b]{2}{*}{ Concordo } & \multirow[b]{2}{*}{$\begin{array}{l}\text { Sem } \\
\text { Opinião }\end{array}$} & \multirow[b]{2}{*}{ Discordo } & \multicolumn{2}{|c|}{ Teste exato de Fisher } \\
\hline & & & & & Valor & $\begin{array}{l}\text { Sig. Exata } \\
\text { (2-abas) }\end{array}$ \\
\hline \multirow{2}{*}{$\begin{array}{l}\text { O SNC é um "fator de promoção, coesão e } \\
\text { internacionalização da profissão" }\end{array}$} & TOC & 20 & 7 & 3 & \multirow{2}{*}{1,552} & \multirow{2}{*}{892} \\
\hline & TC & 15 & 4 & 3 & & \\
\hline \multirow{2}{*}{$\begin{array}{l}\text { O justo valor quando é aplicável, está muito } \\
\text { dependente do juízo profissional e, como tal, } \\
\text { está associado a um risco elevado }\end{array}$} & TOC & 22 & 6 & 2 & \multirow{2}{*}{4,02} & \multirow{2}{*}{,375 } \\
\hline & $\mathrm{TC}$ & 14 & 4 & 4 & & \\
\hline \multirow{2}{*}{$\begin{array}{l}\text { O SNC torna a profissão de técnico de } \\
\text { contabilidade mais arriscada, uma vez que } \\
\text { tem por base princípios e não regras }\end{array}$} & TOC & 23 & 1 & 6 & \multirow{2}{*}{5,705} & \multirow{2}{*}{, 186} \\
\hline & TC & 12 & 2 & 8 & & \\
\hline \multirow{2}{*}{ O SNC potencia o risco de fraude } & TOC & 9 & 9 & 12 & \multirow{2}{*}{4,282} & \multirow{2}{*}{, 370} \\
\hline & TC & 3 & 5 & 14 & & \\
\hline \multirow{2}{*}{$\begin{array}{l}\text { Os conflitos entre os técnicos de contabilidade } \\
\text { e a Administração Fiscal tendem a agravar-se }\end{array}$} & TOC & 13 & 4 & 13 & \multirow{2}{*}{1,945} & \multirow{2}{*}{, 769} \\
\hline & TC & 12 & 3 & 7 & & \\
\hline \multirow{2}{*}{$\begin{array}{l}\text { Com o SNC, a profissão de técnico de } \\
\text { contabilidade vai ser mais controlada pela } \\
\text { CNC e é expectável que sejam aplicadas } \\
\text { coimas a quem não cumprir }\end{array}$} & TOC & 13 & 8 & 9 & \multirow{2}{*}{4,597} & \multirow{2}{*}{, 321} \\
\hline & $\mathrm{TC}$ & 12 & 7 & 3 & & \\
\hline \multirow{2}{*}{$\begin{array}{l}\text { Os conflitos entre os técnicos de contabilidade } \\
\text { e os clientes tendem a agravar-se }\end{array}$} & TOC & 11 & 6 & 13 & \multirow{2}{*}{3,064} & \multirow{2}{*}{,571 } \\
\hline & TC & 6 & 4 & 12 & & \\
\hline \multirow{2}{*}{$\begin{array}{l}\text { Os técnicos de contabilidade necessitam de } \\
\text { mais das informações fornecidas pelos clientes }\end{array}$} & TOC & 22 & 3 & 5 & \multirow{2}{*}{2,479} & \multirow{2}{*}{ 693 } \\
\hline & $\mathrm{TC}$ & 15 & 3 & 4 & & \\
\hline
\end{tabular}

Fonte: Elaboração própria

Os valores do $p$-value são todos superiores a 0,05 , o que nos leva a concluir que a profissão exercida pelo indagado não tem influência significativa sobre a opinião do impacto causado pela adoção do SNC na profissão do TOC.

Efetuando uma análise similar em função do normativo aplicado, verificamos pelas respostas expressas na Tabela 10 que a maioria reconhece a valorização da profissão, os riscos inerente às caraterísticas do SNC e a uma intensificação da colaboração do cliente. Esta é uma possibilidade que pode justificar que os preparadores em modelo geral acreditem que os conflitos com estes não aumentarão, apesar de essa certeza não se verificar do lado dos preparadores em NCRF-PE. Contudo, enquanto os profissionais que utilizam a NCRF-PE acreditam no agravamento das relações com a Autoridade Tributária e de um controlo mais apertado pela $\mathrm{CNC}$, os que exercem a profissão enquadrados no modelo geral têm opiniões mais dispersas sobre esses assuntos.

Para aferirmos se essas diferenças são significativas por razões de normativo testámos as hipóteses seguintes: HO - As opiniões sobre as implicações do SNC na profissão de TOC são independentes do referencial normativo; Ha - As opiniões sobre as implicações do SNC na profissão de TOC não são independentes do referencial normativo. 
Tabela 10

Perceção sobre o impacto do SNC na profissão vs. Normativo aplicado

\begin{tabular}{|c|c|c|c|c|c|c|}
\hline \multirow[b]{2}{*}{ Afirmação } & \multirow{2}{*}{$\begin{array}{l}\text { Modelo } \\
\text { aplicado }\end{array}$} & \multirow[b]{2}{*}{ Concordo } & \multirow{2}{*}{$\begin{array}{c}\text { Sem } \\
\text { Opinião }\end{array}$} & \multirow[b]{2}{*}{ Discordo } & \multicolumn{2}{|c|}{ Teste exato de Fisher } \\
\hline & & & & & Valor & $\begin{array}{l}\text { Sig. Exata } \\
\text { (2-abas) }\end{array}$ \\
\hline \multirow{2}{*}{$\begin{array}{l}\text { O SNC é um "fator de promoção, coesão e } \\
\text { internacionalização da profissão" }\end{array}$} & SNC - geral & 15 & 4 & 5 & \multirow{2}{*}{2,95} & \multirow{2}{*}{, 561} \\
\hline & SNC - PE & 22 & 7 & 2 & & \\
\hline \multirow{2}{*}{$\begin{array}{l}\text { O justo valor quando é aplicável, está muito } \\
\text { dependente do juízo profissional e, como } \\
\text { tal, está associado a um risco elevado }\end{array}$} & SNC - geral & 16 & 7 & 1 & \multirow{2}{*}{6,176} & \multirow{2}{*}{,133 } \\
\hline & SNC - PE & 22 & 3 & 6 & & \\
\hline \multirow{2}{*}{$\begin{array}{l}\text { O SNC torna a profissão de técnico de } \\
\text { contabilidade mais arriscada, uma vez que } \\
\text { tem por base princípios e não regras }\end{array}$} & SNC - geral & 14 & 3 & 7 & \multirow{2}{*}{4,081} & \multirow{2}{*}{, 400} \\
\hline & SNC - PE & 21 & 0 & 10 & & \\
\hline \multirow{2}{*}{ O SNC potencia o risco de fraude } & SNC - geral & 4 & 10 & 10 & \multirow{2}{*}{5,17} & \multirow{2}{*}{, 244} \\
\hline & SNC - PE & 9 & 7 & 15 & & \\
\hline \multirow{2}{*}{$\begin{array}{l}\text { Os conflitos entre os técnicos de } \\
\text { contabilidade e a Administração Fiscal } \\
\text { tendem a agravar-se }\end{array}$} & SNC - geral & 10 & 4 & 10 & \multirow{2}{*}{2,477} & \multirow{2}{*}{, 677} \\
\hline & SNC - PE & 17 & 3 & 11 & & \\
\hline \multirow{2}{*}{$\begin{array}{l}\text { Com o SNC, a profissão de técnico de } \\
\text { contabilidade vai ser mais controlada } \\
\text { pelaCNC e é expectável que sejam aplicadas } \\
\text { coimas a quem não cumprir }\end{array}$} & SNC - geral & 10 & 9 & 5 & \multirow{2}{*}{2,395} & \multirow{2}{*}{,695 } \\
\hline & SNC - PE & 16 & 8 & 7 & & \\
\hline \multirow{2}{*}{$\begin{array}{l}\text { Os conflitos entre os técnicos de contabilidade } \\
\text { e os clientes tendem a agravar-se }\end{array}$} & SNC - geral & 5 & 4 & 15 & \multirow{2}{*}{9,637} & \multirow{2}{*}{,031 } \\
\hline & SNC - PE & 13 & 6 & 12 & & \\
\hline \multirow{2}{*}{$\begin{array}{l}\text { Os técnicos de contabilidade necessitam } \\
\text { de mais das informações fornecidas pelos } \\
\text { clientes }\end{array}$} & SNC - geral & 13 & 6 & 5 & \multirow{2}{*}{6,47} & \multirow{2}{*}{, 128 } \\
\hline & SNC - PE & 25 & 2 & 4 & & \\
\hline
\end{tabular}

Fonte: Elaboração própria

Atendendo aos resultados expressos na Tabela 10, para um nível de significância de 0,05 , não se rejeita a hipótese nula, salvo para a afirmação relativa ao agravamento dos conflitos entre profissionais e clientes, cujo p-value é inferior ao nível de significância. Desse modo, quanto a esse aspeto, as diferenças de opinião variam significativamente em função do normativo contabilístico. A NCRF-PE é utilizada em empresas de menor dimensão, cujas relações entre clientes e preparadores pode, eventualmente, ser mais fechada e difícil no âmbito do fornecimento da informação.

\subsubsection{Perceção sobre o impacto da adoção do SNC nas empresas}

A Tabela 11 ilustra a perceção dos preparadores quanto à alteração no resultado do período provocada pela utilização do SNC em detrimento do POC. A maioria dos respondentes entende que o resultado do período não apresenta alteração de realce. Comparativamente com o estudo que serviu de base (ICAEW, 2007), em termos gerais, as conclusões são idênticas. 
Tabela 11

Perceção sobre o impacto do SNC no Resultado do Período

\begin{tabular}{ccc}
\hline \multirow{2}{*}{ Afirmação } & $\begin{array}{c}\text { O que diria sobre o impacto do SNC na sua empresa relativamente ao resultado do } \\
\text { período obtido, em comparação como o modelo contabilístico anterior? }\end{array}$ \\
\cline { 2 - 3 } & Icaew & Nosso estudo \\
\hline Muito inferior & $4,00 \%$ & $\mathbf{3 , 3 0 \%}$ \\
\hline Pouco inferior & $16,00 \%$ & $\mathbf{1 3 , 1 0 \%}$ \\
\hline Sem alteração & $40,00 \%$ & $\mathbf{5 0 , 8 0 \%}$ \\
\hline Pouco superior & $23,00 \%$ & $\mathbf{2 7 , 9 0 \%}$ \\
\hline Muito superior & $8,00 \%$ & $\mathbf{4 , 9 0 \%}$ \\
\hline & $\mathbf{9 1 , 0 0 \%}$ & $\mathbf{1 0 0 , 0 0 \%}$ \\
\hline
\end{tabular}

Fonte: Elaboração própria

Vejamos se essas conclusões se mantêm quando analisamos os dados de acordo com a profissão desempenhada e o normativo aplicado.

Relativamente à variável "função desempenhada" colocámos as seguintes hipóteses a estudo: HO - A perceção do preparador da informação do impacto do SNC nas empresas é independente da função desempenhada; Ha - A perceção do preparador da informação do impacto do SNC nas empresas não é independente da função desempenhada.

Tabela 12

Perceção sobre o impacto do SNC no Resultado do Período vs. Função desempenhada

\begin{tabular}{|c|c|c|c|c|c|c|c|c|}
\hline \multirow[b]{2}{*}{ Afirmação } & \multirow{2}{*}{$\begin{array}{c}\text { Profissão } \\
\text { Exercida }\end{array}$} & \multirow{2}{*}{$\begin{array}{l}\text { Muito } \\
\text { Inferior }\end{array}$} & \multirow{2}{*}{$\begin{array}{l}\text { Pouco } \\
\text { Inferior }\end{array}$} & \multirow{2}{*}{$\begin{array}{c}\text { Sem } \\
\text { Alteração }\end{array}$} & \multirow{2}{*}{$\begin{array}{l}\text { Pouco } \\
\text { Superior }\end{array}$} & \multirow{2}{*}{$\begin{array}{l}\text { Muito } \\
\text { Superior }\end{array}$} & \multicolumn{2}{|c|}{ Teste exato de Fisher } \\
\hline & & & & & & & Valor & $\begin{array}{c}\text { Sig. Exata } \\
\text { (2-abas) }\end{array}$ \\
\hline \multirow{2}{*}{$\begin{array}{l}\text { O que diria sobre o } \\
\text { impacto do SNC na sua } \\
\text { empresa relativamente } \\
\text { ao resultado do período } \\
\text { obtido, em comparação } \\
\text { como o modelo } \\
\text { contabilístico anterior? }\end{array}$} & TOC & 1 & 6 & 15 & 7 & 1 & \multirow{2}{*}{,050 } & \multirow{2}{*}{,428 } \\
\hline & TC & 0 & 2 & 11 & 7 & 2 & & \\
\hline
\end{tabular}

Fonte: Elaboração própria

Como podemos observar pela Tabela 12, o valor do p-value leva-nos a afirmar que as variáveis são independentes entre si. De tal modo, as opiniões emitidas pelos preparadores da informação financeira não foram influenciadas pela profissão desempenhada.

No caso de filtrarmos os resultados pelo critério do normativo aplicado (Tabela 13), parece apontar que tal não influencia a opinião do indagado. Testámos as seguintes hipóteses: $\mathrm{HO}$ - A perceção do preparador da informação do impacto do SNC nas empresas é independente do normativo aplicado; Ha - A perceção do preparador da informação do impacto do SNC nas empresas não é independente do normativo aplicado. 
Tabela 13

Perceção sobre o impacto do SNC no Resultado do Período vs. Normativo aplicado

\begin{tabular}{|c|c|c|c|c|c|c|c|c|}
\hline \multirow[b]{2}{*}{ Afirmação } & \multirow[b]{2}{*}{$\begin{array}{c}\text { Modelo } \\
\text { Aplicado }\end{array}$} & \multirow[b]{2}{*}{$\begin{array}{l}\text { Muito } \\
\text { Inferior }\end{array}$} & \multirow[b]{2}{*}{$\begin{array}{l}\text { Pouco } \\
\text { Inferior }\end{array}$} & \multirow[b]{2}{*}{$\begin{array}{c}\text { Sem } \\
\text { Alteração }\end{array}$} & \multirow[b]{2}{*}{$\begin{array}{l}\text { Pouco } \\
\text { Superior }\end{array}$} & \multirow{2}{*}{$\begin{array}{c}\text { Muito } \\
\text { Superior }\end{array}$} & \multicolumn{2}{|c|}{ Teste exato de Fisher } \\
\hline & & & & & & & Valor & $\begin{array}{l}\text { Sig. Exata } \\
\text { (2-abas) }\end{array}$ \\
\hline \multirow{2}{*}{$\begin{array}{l}\text { O que diria sobre o } \\
\text { impacto do SNC na sua } \\
\text { empresa relativamente } \\
\text { ao resultado do período } \\
\text { obtido, em comparação } \\
\text { como o modelo } \\
\text { contabilístico anterior? }\end{array}$} & $\begin{array}{l}\text { SNC - } \\
\text { geral }\end{array}$ & 0 & 4 & 11 & 7 & 2 & \multirow{2}{*}{,984 } & \multirow{2}{*}{,0914 } \\
\hline & SNC - PE & 2 & 4 & 16 & 8 & 1 & & \\
\hline
\end{tabular}

Fonte: Elaboração própria

Pelos valores apresentados na Tabela 13, a hipótese nula não será rejeitada dado o valor do nível de significância ser superior ao $p$-value.

Também questionámos o grau de confiança dos preparadores da informação relativamente ao entendimento do impacto da adoção do novo normativo nas DF por parte dos gestores e analistas das suas empresas.

Tabela 14

Nível de confiança relativo ao grau de entendimento do impacto da adoção do SNC por parte dos gestores e analistas

\begin{tabular}{lcc}
\hline \multirow{2}{*}{ Afirmação } & $\begin{array}{c}\text { Em que medida está confiante, que os gestores e analistas da sua empresa } \\
\text { entenderam o impacto do SNC nas DF apresentadas? }\end{array}$ \\
\cline { 2 - 3 } Nada confiante & Icaew & Nosso estudo \\
\hline Pouco confiante & $9,00 \%$ & $\mathbf{9 , 8 0 \%}$ \\
\hline Não sei & $27,00 \%$ & $\mathbf{3 1 , 1 0 \%}$ \\
\hline Confiante & $13,00 \%$ & $\mathbf{2 3 , 0 0 \%}$ \\
\hline Muito confiante & $43,00 \%$ & $\mathbf{3 6 , 1 0 \%}$ \\
\hline & $9,00 \%$ & $\mathbf{0 , 0 0 \%}$ \\
\hline
\end{tabular}

Fonte: Elaboração própria

As opiniões dividiram-se entre duas opções de resposta opostas - "Pouco Confiante" e "Confiante" -, sendo que o somatório das percentagens apresentadas por ambas as opções representa mais de metade da amostra. Do estudo do ICAEW (2007) resultou que uma maioria absoluta está, pelo menos confiante, em relação ao entendimento que os gestores e analistas financeiros têm sobre o impacto causado pela NIC/NIRF na elaboração das DF consolidadas.

Com base na informação recolhida, deduzimos que a profissão desempenhada pouco ou nada influencia as opiniões da amostra. Para consolidarmos esta ideia, testámos as seguintes hipóteses: $H O$ - A perceção do preparador da informação do impacto do SNC nas empresas é independente da função desempenhada; Ha - A perceção do preparador da informação do impacto do SNC nas empresas não é independente da função desempenhada. 
Tabela 15

Nível de confiança relativo ao grau de entendimento do impacto da adoção do SNC por parte dos gestores e analistas vs. Função desempenhada

\begin{tabular}{|c|c|c|c|c|c|c|c|c|}
\hline \multirow[b]{2}{*}{ Afirmação } & \multirow[b]{2}{*}{$\begin{array}{c}\text { Profissão } \\
\text { Exercida }\end{array}$} & \multirow[b]{2}{*}{$\begin{array}{c}\text { Nada } \\
\text { Confiante }\end{array}$} & \multirow[b]{2}{*}{$\begin{array}{l}\text { Pouco } \\
\text { Confiante }\end{array}$} & \multirow[b]{2}{*}{$\begin{array}{l}\text { Não } \\
\text { Sei }\end{array}$} & \multirow[b]{2}{*}{ Confiante } & \multirow{2}{*}{$\begin{array}{c}\text { Muito } \\
\text { Confiante }\end{array}$} & \multicolumn{2}{|c|}{ Teste exato de Fisher } \\
\hline & & & & & & & Valor & $\begin{array}{c}\text { Sig. Exata } \\
\text { (2-abas) }\end{array}$ \\
\hline $\begin{array}{l}\text { Em que medida está } \\
\text { confiante, que os } \\
\text { gestores e analistas }\end{array}$ & TOC & 3 & 11 & 6 & 10 & 0 & \multirow{2}{*}{,687 } & \multirow{2}{*}{,502 } \\
\hline $\begin{array}{l}\text { entenderam o } \\
\text { impacto do SNC nas } \\
\text { DF apresentadas? }\end{array}$ & TC & 3 & 5 & 5 & 9 & 0 & & \\
\hline
\end{tabular}

Fonte: Elaboração própria

O resultado mostra um $p$-value $=0,502$, logo não rejeitamos a hipótese nula. Podemos afirmar, então, que a função desempenhada é independente da opinião emitida pelo preparador quanto ao nível de confiança relativo ao grau de entendimento do impacto da adoção do SNC por parte dos gestores e analistas.

Vejamos agora se o parecer dos indagados foi ou não afetado significativamente pelo normativo aplicado com a aplicação das seguintes hipóteses: $\mathrm{HO}$ - A perceção do preparador da informação do impacto do SNC nas empresas é independente do normativo aplicado e Ha - A perceção do preparador da informação do impacto do SNC nas empresas não é independente do normativo aplicado.

Tabela 16

Nível de confiança relativo ao grau de entendimento do impacto da adoção do SNC por parte dos gestores e analistas vs. Normativo aplicado

\begin{tabular}{|c|c|c|c|c|c|c|c|c|}
\hline \multirow[b]{2}{*}{ Afirmação } & \multirow{2}{*}{$\begin{array}{c}\text { Modelo } \\
\text { Aplicado }\end{array}$} & \multirow{2}{*}{$\begin{array}{c}\text { Nada } \\
\text { Confiante }\end{array}$} & \multirow{2}{*}{$\begin{array}{l}\text { Pouco } \\
\text { Confiante }\end{array}$} & \multirow{2}{*}{$\begin{array}{l}\text { Não } \\
\text { Sei }\end{array}$} & \multirow[b]{2}{*}{ Confiante } & \multirow{2}{*}{$\begin{array}{c}\text { Muito } \\
\text { Confiante }\end{array}$} & \multicolumn{2}{|c|}{ Teste exato de Fisher } \\
\hline & & & & & & & Valor & $\begin{array}{c}\text { Sig. Exata } \\
\text { (2-abas) }\end{array}$ \\
\hline $\begin{array}{l}\text { Em que medida está } \\
\text { confiante, que os } \\
\text { gestores e analistas }\end{array}$ & $\begin{array}{l}\text { SNC - } \\
\text { geral }\end{array}$ & 4 & 6 & 6 & 8 & 0 & \multirow{2}{*}{3,827} & \multirow{2}{*}{,714 } \\
\hline $\begin{array}{l}\text { impacto do SNC nas } \\
\text { DF apresentadas? }\end{array}$ & SNC - PE & 2 & 12 & 6 & 11 & 0 & & \\
\hline
\end{tabular}

Fonte: Elaboração própria

Após a análise aos valores apresentados na Tabela 16, a variável normativo aplicado mostra-se independente da opinião dos preparados.

Por fim, a última questão confronta a qualidade das DF elaboradas de acordo com os dois normativos - POC vs. SNC. Os preparadores da informação financeira responderam de forma quase uníssima, quando questionados sobre a alteração ou não da qualidade da informação das DF, conforme se deduz da Tabela 17, em que cerca de 65\% consideram que a qualidade, pelo menos, melhorou. Neste âmbito, verificamos que entre o nosso estudo e o estudo do ICAEW (2007) parece não existir diferenças significativas na opinião dos preparadores. 
Tabela 17

Perceção sobre o impacto do SNC na qualidade das DF

\begin{tabular}{lcc}
\hline \multirow{2}{*}{ Afirmação } & $\begin{array}{c}\text { Qual o efeito da adoção do SNC na qualidade das DF da sua empresa, em } \\
\text { comparação como o modelo contabilístico anterior? }\end{array}$ \\
\cline { 2 - 3 } & Icaew & Nosso estudo \\
\hline Significativamente pior & $6,00 \%$ & $\mathbf{0 , 0 0 \%}$ \\
\hline Pior & $9,00 \%$ & $\mathbf{9 , 8 3 \%}$ \\
\hline Sem efeito & $25,00 \%$ & $\mathbf{2 4 , 6 0 \%}$ \\
\hline Melhor & $48,00 \%$ & $\mathbf{5 5 , 7 4 \%}$ \\
\hline Significativamente melhor & $12,00 \%$ & $\mathbf{9 , 8 3 \%}$ \\
\hline & $\mathbf{1 0 0 , 0 0 \%}$ & $\mathbf{1 0 0 , 0 0 \%}$ \\
\hline
\end{tabular}

Fonte: Elaboração própria

Vejamos se essa opinião tem algum desvio, começando por filtrar os resultados com base na profissão desempenhada. Assim, testámos as seguintes hipóteses: HO - A perceção do preparador da informação do impacto do SNC nas empresas é independente da função desempenhada; $\mathrm{Ha}$ - A perceção do preparador da informação do impacto do SNC nas empresas não é independente da função desempenhada.

Tabela 18

Perceção sobre o impacto do SNC na qualidade das DF vs. Função desempenhada

\begin{tabular}{|c|c|c|c|c|c|c|c|c|}
\hline \multirow[b]{2}{*}{ Afirmação } & \multirow[b]{2}{*}{$\begin{array}{c}\text { Profissão } \\
\text { Exercida }\end{array}$} & \multirow[b]{2}{*}{$\begin{array}{l}\text { Sig. } \\
\text { Pior }\end{array}$} & \multirow[b]{2}{*}{ Pior } & \multirow[b]{2}{*}{$\begin{array}{c}\text { Sem } \\
\text { Efeito }\end{array}$} & \multirow[b]{2}{*}{ Melhor } & \multirow[b]{2}{*}{$\begin{array}{l}\text { Sig. } \\
\text { Melhor }\end{array}$} & \multicolumn{2}{|c|}{ Teste exato de Fisher } \\
\hline & & & & & & & Valor & $\begin{array}{c}\text { Sig. Exata } \\
\text { (2-abas) }\end{array}$ \\
\hline \multirow{2}{*}{$\begin{array}{l}\text { Qual o efeito da adoção do SNC } \\
\text { na qualidade das demonstrações } \\
\text { financeiras da sua empresa, em } \\
\text { comparação como o modelo } \\
\text { contabilístico anterior? }\end{array}$} & TOC & 0 & 2 & 8 & 19 & 1 & \multirow{2}{*}{6,363} & \multirow{2}{*}{,354 } \\
\hline & $\mathrm{TC}$ & 0 & 2 & 6 & 11 & 3 & & \\
\hline
\end{tabular}

Fonte: Elaboração própria

De acordo com os resultados expressos na Tabela 18, não rejeitamos a hipótese nula, o que nos permite concluir que a opinião emitida sobre a alteração da qualidade da informação financeira com a adoção do SNC é independente da profissão exercida pelo inquirido.

Assentando a análise em função do normativo aplicado, verificamos que as respostas dos preparadores parecem não se diferenciam por utilizarem o modelo geral ou o modelo das pequenas entidades. Testámos então as seguintes hipóteses: HO - A perceção do preparador da informação do impacto do SNC nas empresas é independente do normativo aplicado; $\mathrm{Ha}$ - A perceção do preparador da informação do impacto do SNC nas empresas não é independente do normativo aplicado. 
Tabela 19

Perceção sobre o impacto do SNC na qualidade das DF vs. Normativo aplicado

\begin{tabular}{|c|c|c|c|c|c|c|c|c|}
\hline \multirow[b]{2}{*}{ Afirmação } & \multirow{2}{*}{$\begin{array}{l}\text { Modelo } \\
\text { Aplicado }\end{array}$} & \multirow{2}{*}{$\begin{array}{l}\text { Sig. } \\
\text { Pior }\end{array}$} & \multirow[b]{2}{*}{ Pior } & \multirow{2}{*}{$\begin{array}{l}\text { Sem } \\
\text { Efeito }\end{array}$} & \multirow[b]{2}{*}{ Melhor } & \multirow{2}{*}{$\begin{array}{l}\text { Sig. } \\
\text { Melhor }\end{array}$} & \multicolumn{2}{|c|}{ Teste exato de Fisher } \\
\hline & & & & & & & Valor & $\begin{array}{l}\text { Sig. Exata } \\
\text { (2-abas) }\end{array}$ \\
\hline $\begin{array}{l}\text { Qual o efeito da adoção do SNC } \\
\text { na qualidade das demonstrações }\end{array}$ & $\begin{array}{l}\text { SNC - } \\
\text { geral }\end{array}$ & 0 & 3 & 6 & 11 & 4 & \multirow{2}{*}{5,587} & \multirow{2}{*}{, 433} \\
\hline $\begin{array}{l}\text { comparação como o modelo } \\
\text { contabilístico anterior? }\end{array}$ & SNC - PE & 0 & 2 & 8 & 20 & 1 & & \\
\hline
\end{tabular}

Fonte: Elaboração própria

Atendendo aos valores do teste exato de Fischer exposto na Tabela 19, novamente não rejeitamos a hipótese nula, dado o valor de significância se apresentar inferior ao valor do $p$-value, traduzindo que as variáveis são independentes entre si.

\section{Conclusões}

No âmbito do processo de harmonização contabilística europeia, as empresas portuguesas ou passaram a utilizar as NIC/NIRF da UE ou o SNC (âmbito nacional). A revisão de literatura efetuada permitiu-nos constatar que os diversos estudos efetuados sobre o impacto da transição do POC para as NIC são coincidentes e não corroboram que as diferenças detetadas entre os dois normativos sejam estatisticamente significativas, quer ao nível do capital próprio quer do resultado líquido. Acresce que essas investigações não confirmam o aumento da relevância da informação contabilística após a adoção das NIC. Todavia, essa alteração de modelo normativo condicionou a avaliação financeira das empresas em consequência dos ajustamentos necessários à transição.

O facto de os estudos existentes sobre o impacto da alteração do modelo associado ao POC para a nova filosofia subjacente ao SNC serem na sua maioria apriorísticos, justificou a realização deste estudo decorrido pelo menos um período económico no novo modelo. Com uma amostra constituída por TOC - na sua maioria - e TC, em que mais de metade aplicou outrora o POC, pretendemos conhecer os impactos do SNC no modelo de informação financeira, no exercício da profissão e nas empresas.

Enquanto modelo de informação, o nosso estudo reforça as conclusões do estudo de pré adoção de Santos e Lopes (2011) relativamente ao POC constituir, à data, um modelo desatualizado, de o SNC responder às atuais necessidades de relato financeiro, além de ser realçada a importância da NCRF-PE. Os inquiridos continuam a mostrarem-se bastante confiantes no novo modelo contabilístico, uma vez que se trata de um normativo mais moderno e mais exigente permitindo a comparabilidade a nível nacional e internacional e o acompanhamento da modernização contabilística europeia. Ao contrário do estudo referido, recolhemos evidência de os preparadores entenderem que o SNC é mais vantajoso ao nível dos custos de preparação da informação financeira e tem em conta as caraterísticas e a realidade das empresas nacionais. Cremos, por certo, que a experiência profissional em SNC justifica a alteração de posição dos preparadores da informação financeira.

Ainda no mesmo âmbito de análise, importa salientar que mais de metade dos inquiridos do nosso estudo concordou que o SNC melhorou a qualidade da divulgação nas DF e que elas preparadas, segundo o novo referencial, permitem uma mais fácil utilização destas pelos supervisores e reguladores. Porém, os preparadores encontram-se bastante divididos no que toca à compreensibilidade por parte dos utentes da informação financeira e nas alterações de gestão do negócio provocadas pela adoção do novo normativo. De realçar que estas opiniões vão de encontro às conclusões do ICAEW (2007). 
No âmbito do impacto na profissão, tendo como comparativo o estudo de pré adoção de Santos e Lopes (2011), foi possível concluir que os preparadores acreditam cada vez mais na valorização da profissão, provavelmente em parte justificada pela maior exigência, do que em POC, da utilização do seu julgamento profissional. Porém, ambos os estudos indiciam que a maior subjetividade associada ao SNC (justo valor e filosofia subjacente) torna o exercício da profissão mais arriscado, apesar de a vivência profissional no novo modelo poder vir a ser um fator amenizador deste risco. Noutra perspetiva veja-se que, conforme mostra o nosso estudo, a experiência dos primeiros anos de SNC provocou uma redução substancial de preparadores que consideram que os conflitos com a Autoridade Tributária e com os clientes podem aumentar. Também concluímos que existe uma redução dos preparadores que concordam que o SNC pode ser causa de fraudes e de existir um controlo mais apertado da CNC no que respeita ao exercício da profissão.

Ao nível do impacto nas empresas, a nossa investigação corrobora, de um modo geral, as conclusões do estudo de ICAEW (2007). Os preparadores da informação financeira consideram que o SNC é benéfico, porque responde às atuais necessidades de relato financeiro, tem em conta as caraterísticas e a realidade das empresas nacionais - com especial relevo para a NCRF-PE - permite a comparabilidade a vários níveis, melhora a qualidade da divulgação nas $\mathrm{DF}$, permite uma mais fácil utilização destas pelos supervisores e reguladores, evita a duplicação de custos de preparação e aumenta a reputação da profissão de TOC. Todavia, o SNC encerra o risco de dificuldade da compreensibilidade por parte dos utentes da informação financeira, a dificuldade dos gestores perceberem as consequências do SNC nas suas DF e a evolução no modelo de relato não ser acompanhado por alterações de gestão do negócio - é possível que esta última situação derive da limitação dos gestores referida.

Este estudo tem como limitação a utilização de uma amostragem não probabilística por conveniência, o que significa que a precisão dos resultados é inferior à de uma amostragem probabilística, pelo que os resultados produzidos não devem ser generalizados, restringindo-se apenas aos preparadores inquiridos. Relevamos também a dificuldade na obtenção de um número de respostas considerado razoável. Refira-se ainda que o não cumprimento dos requisitos de aplicação de alguns testes estatísticos restringiu o trabalho que se pretendia efetuar, podendo, eventualmente, ter influenciando algumas das conclusões extraídas da nossa análise.

Como pistas para investigação futura, lançamos o desafio de se estudar o impacto do SNC na ótica de outros agentes, nomeadamente, auditores ou investidores. Pelo facto de o nosso estudo se ter centrado nas empresas com finalidade lucrativa, sugerimos que este estudo seja replicado exclusivamente para entidades que apliquem a norma para o setor não lucrativo, cujo normativo aplicado até à entrada em vigor era diverso entre essas entidades. Por fim, também seria desejável a realização de estudos que permitam aferir do grau de cumprimento ou de assimilação do SNC.

\section{Referências}

Aisbitt, S. (2006). Assessing the effect of the transition to IFRS on equity: the case of FTSE 100. Accounting in Europe, 3(1), 117-133. doi:10.1080/09638180600920293

Alves, M. \& Antunes, E. (2010). A implementação das Normas Internacionais de Contabilidade na Europa: um estudo comparativo. Working Paper da Universidade da Beira Interior, Departamento de Gestão e Economia.. Recuperado de http://www.dge.ubi.pt/investigacao/TDiscussao/TD10_2010.pdf.

Araújo, S. M. A. (2010). Impacto da aplicação das normas internacionais de contabilidade nas empresas do PSI 20. Dissertação de Mestrado. Universidade Técnica de Lisboa. Instituto Superior de Economia e Gestão.

Athanasios, B., Kanellos, T. \& Konstanyinos, P. (2007). The consequences of applying International Accounting Standards (IAS) to the financial statements of Greek companies. Working Paper. Recuperado de http://ssrn.com/abstract=985048. 
Bell, J. (1993). Como realizar um projecto de investigação. Lisboa: Gradiva.

Callao, S., Jarne, J. \& Laínez, J. (2007). Adoption of IFRS in Spain: effect on the comparability and relevance of financial reporting. Journal of International Accounting, Auditing and Taxation, 16(2), 148-178. DOI:10.1016/j.intaccaudtax.2007.06.002.

CNC (2008). Apresentação do projeto Sistema de Normalização Contabilística. Lisboa. Recuperado 09 março, 2013 de http://www.cnc.min-financas.pt/Documentos/SNC\%20_apr_16abr08.pdf .

CNC (2010). A perspetivada CNC (observatório SNC 2010). Conferência: O SNC em 2010. Lisboa. Recuperado em 30 abril, 2013, de http://www.cnc.minfinancas.pt/0_new_site/Conferencia_dez2010/ Painel_1_PedroAleixoDias_Conferencia2010.pdf.

CNC (2011). A atividade da CNC: desafios e dificuldades na atuaçãoda CNC (observatório SNC 2011). Lisboa. Recuperado em 30 abril, 2013, de http://www.cnc.minfinancas.pt/0_new_site/Conferencia2011/Painel_1_Dr_Pedro_Aleixo_Dias.pdf.

Cordeiro, R., Couto, G. \& Silva, F. (2007). Measuring the impact of International Financial Reporting Standards (IFRS) in firm reporting: the case of Portugal. Working Paper. Recuperado em 21 abril, 2013 de http://papers.ssrn.com/sol3/papers.cfm?abstract_id=969972.

Correia, L. (2009). SNC vs. POC: uma primeira abordagem. Revisores \& Auditores. 46, 28-36.

Costa, J. \& Lopes, P. (2010). O impacto da adopção das IAS/IFRS nas demonstrações financeiras das empresas cotadas na Euronext Lisboa. Contabilidade e Gestão. 9, 49-80.

Ferreira, A. \& Ferreira, J. (2008). A Opção por um modelo de Normalização Contabilística. Jornal de Contabilidade. 32(380), 359-366.

Grenha, C., Cravo, D., Batista, L. \& Pontes, S. (2009). Anotações ao sistema de normalização contabilística. Lisboa: CTOC. ISBN: 978-989-95224-5-9.

Guerreiro, M. (2006). Impacto da adopção das International Financial Reporting Standards: factores explicativos do nível de informação divulgada pelas empresas portuguesas cotadas. Contabilidade e Gestão, 3, 7-32.

Hill, M. \& Hill, A. (2008). Investigação por Questionário. (2 ed.). Lisboa: Edições Sílabo. ISBN: 972-618273-5.

Hung, M. \& Subramanyam, K. (2007). Financial Statement Effects of Adopting International Accounting Standards: The Case of Germany. Review of Accounting Studies, 12(4), 623-657.

ICAEW (2007). EU implementation of IFRS and the fair value directive: a report for the European Commission. 34-42. ISBN 978-1-84152-520-4.

Jermakowicz, E. (2004). Effects of adoption of International Financial Reporting Standards in Belgium: the evidence from BEL-20 companies. Accounting in Europe, 1(1), 51-70. doi: $10.1080 / 0963818042000270811$

Machado, J. (2012). Os primeiros impactos da adoção do SNC nas PME de excelência em Portugal. Dissertação de Mestrado. Minho: Universidade do Minho Escola de Economia e Gestão.

Maroco, J. (2007). Análise estatística: com utilização do SPSS. (3 ed.). Lisboa: Edições Sílabo. ISBN: 978972-618-452-2.

Pestana, M. \& Gageiro, J. (2008). Análise de dados para Ciências Sociais: a complementaridade do SPSS. (2 ed.). Lisboa: Edições Sílabo. ISBN: 972-618-220-4.

Pinheiro, M. \& Lopes, I. (2012). A Qualidade da Informação Contabilística Antes e Após a Adoção das Normas Internacionais de Contabilidade: O Caso Português. Contabilidade e Gestão. 13, 9-48.

Pinto, J. (2009). Normalização contabilística internacional. Jornal de Negócios. Nota n. ${ }^{\circ}$ 570-C. 
Pires, A. (2009). Sistema de normalização contabilística: do POC ao SNC. Lisboa: Publisher Team. ISBN: 978-989-601-0.

Pires, A. (2010). Os efeitos e implicações da actual reforma contabilística (SNC) no quadro das relações de coexistência entre a contabilidade e a fiscalidade. Anais do Encontro da AECA - Associación Española de Contabilidad y Administración. Bragança ISBN: 978-84-96648-43-2.

Quagli, A. \& Paoloni, P. (2012). How is the IFRS for SME accepted in the European context? An analysis of the homogeneity among European countries, users and preparers in the European commission questionnaire. Advances in Accounting, incorporating Advances in International Accounting, 28(1), 147-156.

Quivy, R. \& Campenhoudt, L. (2008). Manual de investigação em ciências sociais. Tradução de J. M. Marques, M. A. Mendes e M. Carvalho. (5 ed.). Lisboa: Gradiva Publicações (Obra original publicada em 1995). ISBN: 978-972-662-275-8.

Ribeiro, I. (2010). Impacto das Normas Contabilísticas e de Relato Financeiro nas Empresas Portuguesas, de acordo com a percepção dos TOC’s. Dissertação de Mestrado. Lisboa: Universidade Técnica de Lisboa Instituto Superior de Economia e Gestão.

Rodrigues, L. (2010). A adopção pela primeira vez do SNC: a norma contabilística e de relato financeiro 3 (NCRF 3). Revista TOC, Edição especial SNC, 31-36.

Santos, M.J. \& Lopes, P. (2010). Os profissionais da contabilidade e o Sistema de Normalização Contabilística (SNC). Sistema de Normalização Contabilística - Jornadas de Contabilidade e Fiscalidade. Porto: Vida Económica. ISBN: 978-972-788-374-5. p. 245-259.

Santos, M.J. \& Lopes, P. (2011). A Percepção dos Profissionais da Contabilidade Sobre a Adopção do Sistema de Normalização Contabilística (SNC). Anais do Congresso de Contabilidade e Auditoria: A change in management. Porto, 13. 